\title{
O controle interno como ferramenta da gestão para cooperativas do Rio Grande do Sul: um estudo de caso
}

\author{
Internal control as a tool of management for cooperative Rio Grande do Sul: a case \\ study
}

\begin{abstract}
Resumo
As mudanças significativas no comportamento do mercado despertam a necessidade da adoção de novos processos e ferramentas de gestão de modo a tornar as organizações cooperativas mais competitivas e sustentáveis. Dessa forma, o objetivo geral desse trabalho é "identificar e analisar as ferramentas de controle interno de uma cooperativa do Estado do Rio Grande do Sul". Sendo assim, tomou-se como referência o modelo de controle interno definidos por Crepaldi (2007). Em termos metodológicos esse trabalho teve como aporte uma pesquisa qualitativa, apoiada em procedimentos de pesquisa de campo, descritiva e exploratória. O método foi estudo de caso que permitiu a investigação profunda dos aspectos teóricos e sua aplicabilidade no contex to prático de uma cooperativa. As técnicas metodológicas adotadas foram coleta, análise e organização dos dados. Para obtenção das respostas relativas ao problema foram utilizadas entrevistas, questionários, análise documental e observação direta. Essencialmente para a análise dos resultados foram adotadas algumas técnicas como: categorização, estatística quantitativa percentual e, essencialmente, análise de conteúdo. Por fim, com base nesse relato pormenorizado dos resultados, acerca das ferramentas de controle interno praticadas pela Cotrijui, concluiu-se, que as rotinas e os procedimentos atende em grau médio, ao modelo de Crepaldi (2007).
\end{abstract}

Palavras-chave: Controle Interno. Sociedades Cooperativas. Cotrijui.

\begin{abstract}
Significant changes in market behavior arouse the need to adopt new processes and administration of tools to make them more competitive and sustainable cooperative organizations. Thus, the aim of this study is to "identify and analyze the tools of internal control of a cooperative of the Rio Grande do Sul state". So we took as reference the internal control model defined by Crepaldi (2007). In terms of methodology this study was to supply a qualitative study, based on field research procedures, descriptive and exploratory. The method was the case study that allowed the thorough investigation of the theoretical aspects and its application in the practical context of a cooperative. The methodological techniques used were gathering, analysis and organization of data. To obtain the answers on the problem interviews were used, questionnaires, document analysis and direct observation. Essentially for the analysis of results were adopted some techniques such as categorization, percentage quantitative statistical and essentially content analysis. Finally, based on this detailed account of the results, concerning the internal control tools applied by Cotrijui, it was concluded that the routines and procedures meets in average degree, the model Crepaldi (2007).
\end{abstract}

Keywords: Internal Control. Cooperative Societies. Cotrijui.

Recebido: 26/11/2014 Aceito: 21/01/2015

Carla Rosane da Costa Sccott ${ }^{1}$ e Leoni Pentiado Godoy ${ }^{2}$

${ }^{1}$ Universidade Federal de Santa Maria, Mestre em Engenharia de Produção - carlasccott@gmail.com

${ }^{2}$ Universidade Federal de Santa Maria, Doutora em Engenharia de Produção - leoni_godoy@yahoo.com.br 


\section{Introdução}

A globalização das economias vem se desenvolvendo de forma acelerada, impondo que as organizações se adaptem a esta nova ordem. As mudanças significativas no comportamento do mercado despertam essas necessidades, permitindo a adoção de novos processos e ferramentas de gestão de modo a torná-las mais competitivas e sustentáveis dentro de uma ótica geral de mercado.

Tálamo e Carvalho (2004) fazem menção à criação de uma nova ordem econômica, pautada por formas diferenciadas quanto ao controle organizacional com ênfase na competitividade e na sustentabilidade.

Pinheiro e Silva (2010, p. 3) assinalam que "o cooperativismo evoluiu e conquistou um espaço próprio, definido por uma nova forma de pensar o homem, o trabalho e o desenvolvimento social".

Ao longo dos anos as organizações cooperativas têm enfrentado uma série de dificuldades para se adaptarem à elevada competição entre os diferentes tipos de organizações. Diante desse cenário, impele a necessidade de reestruturação de suas condições gerenciais sob a ótica da revisão de princípios, profissionalização da gestão, reordenação das estruturas de custos, dos sistemas de controle e medição dos resultados, das ferramentas de avaliação interna, dos critérios de busca e fidelização dos associados, dos instrumentos de gestão da informação e do conhecimento, dentre outros elementos.

Desta forma, ganha relevância a constituição de cooperativas sob uma estrutura formalizada sob o ponto de vista das questões do controle como forma essencial de oferecer instrumentos condicionantes de uma melhor gestão organizacional.

Por analogia, toda organização possui instrumentos próprios de controle. Porém a diferença básica é que esses podem ser adequados ou não ao exercício efetivo de suas atividades. Associados aos fundamentos da gestão, Zanette, Nascimento e Alberton (2009, p. 2) contribuem no sentido de que "a contabilidade como segmento profissional, reafirma a sua verdadeira importância no cenário econômico-empresarial, pois apresenta condições de subsidiar com informações financeiras e gerenciais em benefício da gestão eficiente do empreendimento cooperativista".

Pereira et al. (2009) expõem que a mensuração do desempenho organizacional é um processo permanente e repetitivo, havendo razões importantes para tal ação em termos de monitoramento do progresso e correção de eventuais erros.

Embora o cooperativismo possua uma forte vertente social, isso não o exime de competir no mercado frente a empresas capitalistas globalizadas e altamente eficientes, demonstrando a necessidade clara de orientação e avaliação das atividades como um todo.

Nesse sentido, Cordeiro e Dantas (2008, p. 4) men- cionam que "são grandes os desafios enfrentados por todo o sistema cooperativista, para sobreviver no atual ambiente competitivo e manter-se fiel ao cumprimento de seus princípios doutrinários".

Assim, Boesche e Mafioletti (2005) destacam que manter o equilíbrio entre as dimensões do social e o econômico é o principal desafio do cooperativismo, já que o ambiente de competição das cooperativas é o mesmo de todas as outras organizações.

Por isto, as cooperativas precisam ser economicamente eficientes, para se manterem no mercado, mas sem deixar de lado a finalidade social em relação aos seus associados. No entanto, Bialoskorski Neto (2001) argumenta que desempenho econômico e de mercado é condição fundamental para o bom desempenho social das cooperativas.

Com isso, parte-se do pressuposto de que o estreitamento das ações de controle interno é necessário à manutenção da competitividade organizacional e que as estruturas organizacionais colaborativas são fundamentais para potencializar e viabilizar esses processos de modo a aumentar sua eficácia. Assim, essa maior potencialidade organizacional pode ser considerada como um elemento de competitividade que, ao ser coordenada, tende a proporcionar as cooperativas um maior potencial inovador e, por consequência, maior sustentabilidade no mercado. Portanto, com maior competitividade e melhor desempenho econômico, as cooperativas podem oferecer mais e melhores benefícios aos seus associados.

De modo bastante consistente, fica claro que há uma visível necessidade de atentar às demandas presentes nas questões que abarcam as questões de controle interno adotado pelas cooperativas. Uma explicação que exige uma ampliação na discussão teórica-prática de modo a fortalecer ainda mais o segmento cooperativo a tornarse cada vez mais competitivo e sustentável nos mais diferentes mercados em que atua.

Dessa forma, a questão central que norteou o problema de pesquisa e que instigou este trabalho foi "identificar e analisar as ferramentas de controle interno de uma cooperativa do Estado do Rio Grande do Sul".

Justifica-se isso, pois as organizações são agentes com necessidades infinitas e renováveis de conhecimento, que implica no uso de instrumentos de controle interno diversificados que permitam o desenvolvimento de ações efetivas quanto à questão da adaptação ao ambiente competitivo. Embora os diferentes modelos de gestão e controle interno coexistam, o foco principal deste estudo está na relação desses elementos e suas contribuições para a promoção de valor agregado, competitividade e sustentabilidade.

A alta competitividade exige constante atualização de seu ambiente e de suas tendências e, com mudanças tão velozes e inovadoras é preciso deixar de pensar operacionalmente e começa-se a pensar estrategicamente. 
Desta forma, o estudo da estratégia se desenvolveu pela tentativa de explicar e buscar uma forma de dirigir as organizações para a obtenção da vantagem competitiva, assim como pela deficiência de outras disciplinas nesse sentido (PADILHA, MATTOS e BARBIERO, 2011).

Por essas razões supõe-se que um estudo desta natureza pode contribuir sobremaneira para a academia e para o desenvolvimento da gestão das cooperativas focadas no aumento da competitividade e da promoção da sustentabilidade em todas as suas dimensões.

\section{Referencial téorico}

Segundo a literatura atual, um sistema de controle interno efetivo tem como objetivo proporcionar a continuidade do fluxo das operações das organizações, gerando informações relevantes para os gestores.

Isso significa que erros e procedimentos ilegais ou fraudulentos poderão ser evitados e, na sua ocorrência, serão detectados e corrigidos dentro de curto prazo, como parte de suas funções habituais (RESKE FILHO, JACQUES e MARIAN, 2005).

Horngren, Sundem e Stratton (2004) consideram que os gestores empresariais estão reconhecendo, cada vez mais, a importância das medidas de controles eficazes. $\mathrm{O}$ controle interno de uma empresa é um assunto correntemente discutido no meio acadêmico e empresarial, dadas as vantagens em eficiência, redução de custos, controle e competitividade que esta gestão pode proporcionar aos agentes envolvidos neste processo.

Dentro desse contexto, entendem-se como controles internos todos os instrumentos destinados à vigilância, fiscalização e verificação administrativa, que permitam prevenir, detectar e corrigir causas de exposição da empresa, mesmo que o fato já tenha ocorrido, não impedindo tais prejuízos (FRANCO e MARRA, 2007).

Conforme salientam os mesmos autores, pode-se afirmar que existem diversas vantagens para as empresas adotarem políticas que utilizem a prática dos controles internos, dentre as quais se destacam: redução de custos, maior confiança na organização por parte dos sócios ou investidores, comprometimento e participação dos colaboradores e maior qualidade organizacional. Controles eficientes possibilitam que organização e colaboradores cumpram com os objetivos de maneira correta e tempestiva, com a mínima utilização de recursos.

Controle interno é o processo planejado, implementado e mantido pelos responsáveis da governança, administração e outros funcionários para fornecer segurança razoável quanto à realização dos objetivos de uma entidade no que se refere à confiabilidade dos relatórios financeiros, efetividade e eficiência das operações e conformidade com leis e regulamentos aplicáveis. O termo "controles" refere-se a quaisquer aspectos de um ou mais dos componentes do controle interno. (NORMA BRASILEIRA DE CONTABILIDADE - NBC TA 315, 2010, p. 30).

O modelo teórico que sustentará a fundamentação pertinente ao controle interno está presente nas considerações de Crepaldi (2007), cuja metodologia assinala para a adoção de alguns princípios que auxiliam no desenvolvimento dessa ferramenta de gestão, sendo eles: responsabilidade, rotinas internas, acesso aos ati-

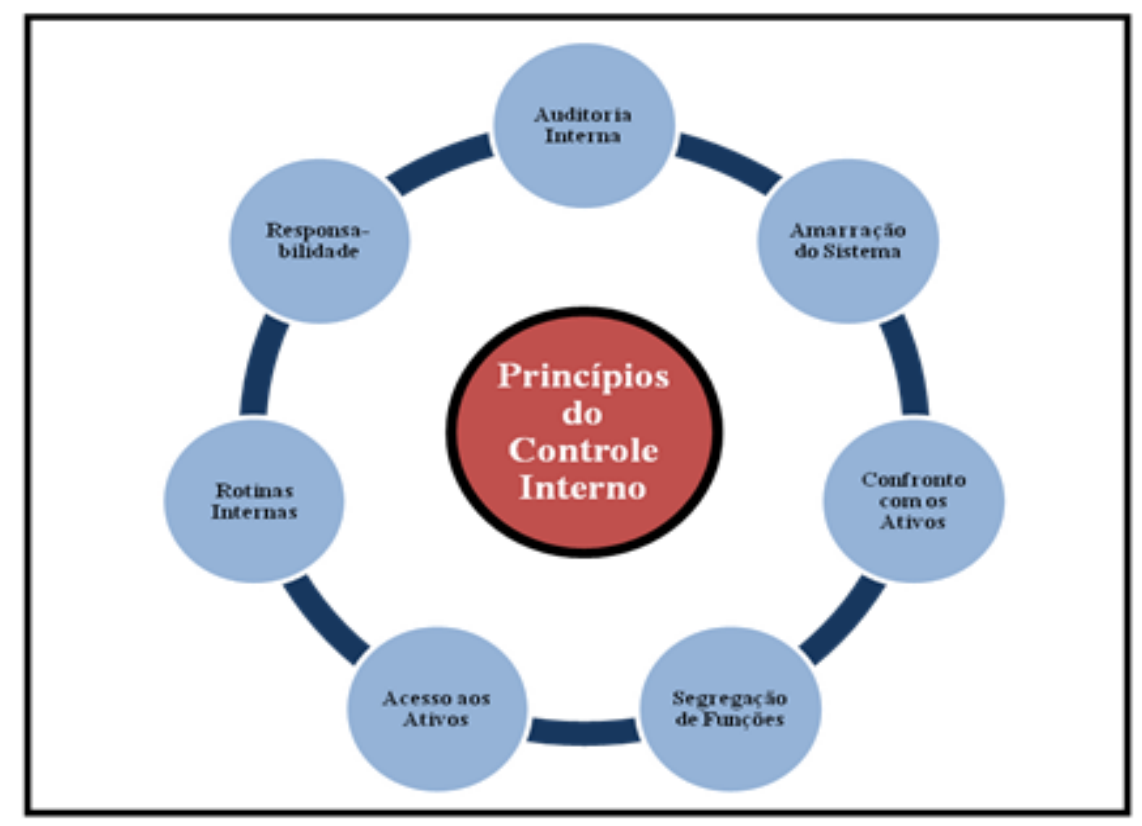

Figura 1 - Princípios do controle interno

Fonte: adaptado Crepaldi (2007). 
vos, segregação de funções, confronto com os ativos, amarração do sistema e auditoria interna. A figura 1 a seguir expressa essa ideia com maior clareza.

Crepaldi (2007) assevera que o princípio da responsabilidade indica atribuições para os funcionários, devendo ser claramente definidos e limitados, de preferência por escrito, mediante as normas estabelecidas pela administração da empresa. As razões para se definir essas atribuições são: assegurar que todo o procedimento interno da empresa esteja sendo realizado de forma correta, detectar erros e irregularidades, apurar as responsabilidades por eventuais omissões, erros ou outro tipo de falha. Numa organização, a observância desse princípio é de extrema relevância, pois é através deste que existem programas de normatização de rotinas e procedimentos. Destacam-se como características desse princípio: a distribuição e delegação de atribuições e responsabilidades; a clareza de limites de alçada; diretrizes e normas legais; existência de qualidade; treinamento e rodízio de funcionários e; principalmente a possibilidade de evitar possíveis desperdícios de recursos, que podem afetar diretamente a gestão e o resultado da empresa.

Martins (2003) complementa que a tarefa de estabelecimento das atribuições de atividades individuais, de preparação das rotinas de execução do trabalho e do planejamento e utilização dos relatórios de desempenho, revela o trabalho de equipe e de liderança, podendo proporcionar oportunidades para que haja uma perfeita integração entre todos os membros da empresa. Com isso, as pessoas ficam motivadas de modo que participam com seu esforço e competências individuais para formulação das diretrizes a serem adotadas.

De acordo com Attie (1998), as rotinas internas de controle indicam a utilização de instrumentos de controles internos, ou seja, formulários, carimbos e outros mecanismos, que evidenciam e garantem que os procedimentos de controles internos sejam executados conforme as normas legais e normas impostas pela empresa.

Na ótica de Crepaldi (2007), são exemplos de instrumentos de rotinas internas de controle: requisição de material ou serviço, ordem de compra (para formalizar a compra com o vendedor), relatórios de prestação de contas de adiantamento para viagem, carimbos de recebimento constando assinatura e data de recebimento na nota fiscal de compra, correspondente a mercadorias adquiridas para revenda, carimbo e autenticação de documentos recebidos ou pagos, entre outros. $\mathrm{O}$ mesmo autor complementa, para que esses instrumentos sejam válidos, devem conter assinaturas (a punho ou eletrônicas), data e controle de sequência numérica, quando se tratar de formulários.

Lopes de Sá (2000) discorre que o princípio do acesso aos ativos indica métodos de segurança que visam resguardar controlar a existência física de ativos, fixar limites de autoridade para realizar determinada operação. Para isso, é importante que a empresa implante meios limitantes ao acesso dos mesmos, de modo que não interfira no desempenho normal das atividades diárias.

São exemplos de controles físicos sobre ativos: local fechado para o caixa guardar títulos em cofres, crachás de identificação para empregados e visitantes no estoque, controle de entrada e saídas de mercadorias, sistema de senha para o acesso ao sistema eletrônico de processamento de dados, entre outros (CREPALDI, 2007).

Para Attie (1998), o princípio da segregação de funções consiste em que uma pessoa não tenha o domínio completo sobre uma determinada operação. É uma medida preventiva para que qualquer erro intencional ou não que ela cometa possa ser detectado de imediato por outra pessoa.

O mesmo autor contribui com exemplos de fatos que podem ocorrer com a falta de observância quanto ao princípio de segregação de funções: a) colaborador que tenha acesso aos ativos (dinheiro, peças em estoque, duplicatas a receber) e aos registros contábeis, pode facilitar a fraude desviando fisicamente o ativo e baixá-lo contabilmente para despesas, o que ocultaria permanentemente essa transação; $b$ ) outro exemplo que pode ser mencionado é no caso de um operador de caixa que ao receber algum numerário pode alterar o lançamento do título em uma conta que represente perdas com clientes, apossando-se do ativo.

Attie (1998) corrobora que o princípio do confronto dos ativos com os registros recomenda que os ativos da entidade (dinheiro, cheques, títulos de créditos, estoque, entre outros), sob responsabilidade de alguém (funcionários ou terceiros), sejam periodicamente confrontados com os registros da contabilidade e de controles internos. O objetivo é detectar fraude de bens ou até mesmo de registro contábil inadequado de ativos.

Crepaldi (2007) auxilia no entendimento através de exemplos desse confronto: contagem física do caixa e comparação com o saldo dos relatórios contábeis, conciliações bancárias (comparação do saldo do extrato enviado pelo banco com o livro razão da contabilidade), inventários físicos dos bens do estoque e do ativo imobilizado, em confronto com os registros individuais e comparação do somatório dos saldos desses registros com o saldo do livro razão.

Outro princípio trata da amarração do sistema, uma vez que destaca que todas as operações da empresa sejam registradas com correção, tanto em termos de valores, quanto de quantidade, que sejam devidamente autorizadas e que qualquer falha seja possível ser detectada (CREPALDI, 2007).

Na ótica de Attie (1998) esse fato exige uma série de providências, tais como: conferência dos registros de controles internos por uma segunda pessoa, confronto dos documentos originais com os registros contábeis gerados automaticamente por sistemas eletrônicos de processamento de dados, controles sequenciais da numeração dos documentos de controle interno, conferência 
independente de cálculos (depreciações, provisões de férias $13^{\circ}$ salário, imposto de renda, entre outros.).

Finalmente, para Lopes de Sá (2000) o princípio da auditoria interna, pode-se dizer que é o mais importante, porque a falta de observância deste pode consistir no não funcionamento dos demais princípios. Para o autor, não adianta a organização implantar um excelente sistema de controle interno, sem que alguém verifique periodicamente se os funcionários estão cumprindo o que foi determinado no planejamento, ou se há necessidade de serem adaptadas às novas técnicas adequadas às necessidades da empresa. Crepaldi (2007) contempla que os objetivos da auditoria interna são: verificar se as normas internas estão sendo seguidas; avaliar a necessidade de novas normas internas ou de notificações das já existentes e identificar ocorrência de possíveis fraudes e/ou irregularidades.

\section{Procedimentos metodológicos}

Lakatos e Marconi (2001) consideram que a pesquisa constitui um procedimento reflexivo, sistemático, controlado e crítico que permite descobrir novos fatos ou dados, em qualquer campo de conhecimento.

Em se tratando de abordagem, esta proposta de trabalho caracteriza-se como sendo qualitativa, pois está centrada na interpretação dos fenômenos e na atribuição de significados. Isso é comprovado pelo fato de buscar a identificação das influências dos processos de gestão e controle interno, sem deixar de considerar suas implicações dentro da organização-alvo.

Sampieri, Collado e Lucio (2006) contextualizam que o enfoque qualitativo é utilizado para descobrir e refinar as questões de pesquisa. Com frequência esse enfoque está baseado em métodos de coleta de dados sem medição numérica, como as descrições e as observações.

Em se tratando de procedimentos, o presente trabalho caracteriza-se, de modo inicial, como uma pesquisa de campo. Lakatos e Marconi (2001, p. 186) assinalam que a pesquisa de campo é "utilizada com o objetivo de conseguir informações ou conhecimentos acerca de um problema, para o qual se procura uma resposta, ou de uma hipótese ou ainda descobrir novos fenômenos ou relações".

Associadas a essa concepção, esse estudo concentra uma pesquisa do tipo descritiva. Cervo e Bervian (2006) consideram que a pesquisa descritiva observa, registra, analisa e correlaciona fatos ou fenômenos sem a interferência do pesquisador, abordando problemas a serem estudados e cujo registro não consta documentado.

Adicionalmente, essa pesquisa está centrada no caráter exploratório, onde Silva (2006) assinala que esse tipo de pesquisa caracteriza-se por fornecer critérios sobre a situação-problema e identificar cursos alternativos de ação. Isso permite inferir que a pesquisa exploratória tem como finalidade examinar um tema ou problema de pesquisa pouco estudado, do qual se tem dúvidas que ainda não foram sanadas com clareza.

Hair Jr. (2006) assinala que há tipologias para se trabalhar os procedimentos de pesquisa, sendo uma delas o estudo de caso. Na ótica de Gil (2009, p. 5), “o estudo de caso pode ser considerado um delineamento em que são utilizados diversos métodos ou técnicas de coleta de dados, como, por exemplo, a observação, a entrevista e a análise de documentos". Outra contribuição apresenta-se pelas considerações de Yin (2003, p. 32) contemplando que "um estudo de caso é uma investigação empírica que analisa um fenômeno contemporâneo dentro do seu contexto, especialmente quando os limites entre o fenômeno e o contexto não estão claramente definidos".

Para contextualizar o caso, a delimitação do universo se faz necessária, pois compreende o conjunto de elementos mensuráveis a respeito das características que se pretende levantar. Identificou-se para o processo de investigação a COTRIJUI - Cooperativa Agropecuária e Industrial, localizada na Cidade de Ijuí, RS.

A escolha por essa organização se deu, em nível amplo, em função da significativa importância econômica e social dessa cooperativa e em nível específico, pelas dificuldades enfrentadas pela cooperativa, especialmente do ponto de vista financeiro, que pode ser evidenciado devido á algumas limitações do ponto de vista do controle interno.

Em termos de técnicas de pesquisa, Ruiz (2004) advoga que estas representam a utilização de diversos recursos peculiares a cada objeto de pesquisa, dentro das etapas do método. Para tanto, inferem-se como técnicas as formas pelas quais os dados serão obtidos, analisados e organizados.

Para a obtenção das respostas relativas às questões levantadas pelo presente estudo, foi elaborado um questionário semiestruturado, como perguntas abertas e fechadas, para a realização da coleta dos dados, bem como de um roteiro de entrevistas aplicado.

Na primeira, foi feito contato com a cooperativa a fim de que se agendasse data e hora para a aplicação dos questionários e a realização das entrevistas. Já a segunda etapa foi, efetivamente a coleta, que se operacionalizou por meio de questionários aplicados e entrevistas realizadas com as pessoas responsáveis por coordenar os processos de gestão e controle interno, localizadas nos níveis estratégico e tático da cooperativa. Tal coleta realizou-se no primeiro semestre de 2013.

Essas entrevistas foram realizadas com grau de profundidade considerável por entender essa como uma forma de coleta essencial. Nesse caso, a entrevista em profundidade foi um recurso metodológico que buscou, com base em teorias e pressupostos definidos, recolher respostas a partir da experiência subjetiva das fontes investigadas, que foram selecionadas por deter informações que se deseja conhecer. Essas entrevistas possibilitaram 
ainda identificar oportunidades de melhoria, interações, padrões e detalhes. Além disso, obteve-se uma ampla qualidade de interpretações, caracterizadas pela riqueza das respostas, associada à explicação de fenômenos que não seriam percebidos por aplicação de questionários, análise documental e observação direta.

Os entrevistados foram indicados pela cooperativa, pois para atender aos objetivos da pesquisa, essas pessoas são as que detêm maior acesso ao conjunto de informações acerca das ferramentas de gestão e das práticas de controle interno, aplicadas nas rotinas de trabalho da cooperativa. Nesse sentido, foram entrevistados o presidente da cooperativa, o vice-presidente, o superintendente, bem com o gerente administrativo. Essas pessoas ajudaram a produzir um mapa claro das questões essenciais dessa investigação e ofereceram subsídios que por si só já seriam suficientes para concluir o processo de investigação.

No entanto, para garantir maior fidelidade das informações e evitar vieses quanto às ações efetivamente empreendidas na rotina da cooperativa, a esses mesmos gestores, bem como a outras pessoas que atuam na cooperativa, aplicou-se um questionário produzido a partir de um conjunto de categorias de análise e suas respectivas variáveis, cuja estrutura visual pode ser observada no quadro 1. tivo, bem como pelo supervisor geral, pelo supervisor do setor de suinocultura, pelo gerente contábil, pelo gerente financeiro, pelo diretor de varejo, pelo assessor administrativo, pelo analista contábil, pelo assessor do varejo e pela secretária da diretoria. Todos esses respondentes foram indicados pelos gestores da cooperativa, dada sua área de atuação e, especialmente, pelo nível de conhecimento acerca dessas temáticas aqui investigadas. No total então, foram aplicados 13 questionários que permitiram correlacionar respostas, produzir estatística simplificada e oferecer condições para produzir algumas ilustrações. Entendeu-se que essas entrevistas e questionários aplicados contribuíram sobremaneira para qualificar e quantificar as respostas necessárias de modo que se pudesse atender ao objetivo do trabalho.

No entanto, entendeu-se ainda que para dar o suporte necessário à investigação, os processos de análise documental e observação direta permitiram complementariedades importantes para que se entendessem os procedimentos de controle interno em todas as suas concepções.

Com base nessas técnicas, entende-se atendidas as condições primordiais para promover a análise das informações obtidas. Conforme Hair Jr. (2006) a análise dos resultados tem como objetivo principal permitir o estabelecimento das conclusões.

\begin{tabular}{|l|l|}
\hline \multicolumn{1}{|c|}{ Elementos de Análise } & \multicolumn{1}{c|}{ Variáveis } \\
\hline Princípio da Responsabilidade & - Atribuições \\
\hline Princípio das Rotinas Internas & $\begin{array}{l}\text { - Instrumentos e mecanismos } \\
\text { - Orientações }\end{array}$ \\
\hline Princípio do Acesso aos Ativos & - Medidas físicas \\
\hline Princípio da Segregação de Funções & $\begin{array}{l}\text { - Segregação de funções } \\
\text { - Autofiscalização }\end{array}$ \\
\hline Princípio do Confronto com os Ativos & $\begin{array}{l}\text { - Contagem física } \\
\text { - Confronto de registros }\end{array}$ \\
\hline Princípio da Amarração do Sistema & - Integração do sistema \\
\hline Princípio da Auditoria Interna & $\begin{array}{l}\text { - Controle e análise } \\
\text { - Independência }\end{array}$ \\
\hline
\end{tabular}

Quadro 1 - Proposta metodológica

Fonte: elaborado pela autora

Essa proposta metodológica teve como proposição constituir-se como elemento guia do processo de investigação necessário a condicionar o estabelecimento de que forma seriam construídos o roteiro de entrevistas e os questionários, bem como as questões complementares sobre a análise documental e a observação direta.

Sendo assim os questionários foram respondidos também pelo presidente da cooperativa, pelo vice-presidente, pelo superintendente, pelo gerente administra-
Com relação às informações qualitativas, foi realizada a análise de conteúdo e ao longo do processo de discussão dos resultados, estas informações serviram como elementos de aprofundamento e entendimento dos dados quantitativos. A análise de conteúdo consiste em uma técnica de pesquisa que pode tornar retráteis e válidas as inferências dos dados referentes ao seu contexto (BELL, 2008).

Uma vez que os dados foram coletados e analisa- 
dos, tem-se a necessidade de organiza-los de forma a promover melhor visualização plena dos mesmos, uma vez que a organização dos dados compreende a forma como os dados serão apresentados. Esses dados serão apresentados na sequência.

\section{Resultados e discussão}

\subsection{A Cooperativa Agropecuária e Industrial - COTRIJUI}

Em meados da década de 1950, a agricultura brasileira enfrentava grandes desafios, faltavam locais para armazenagem e principalmente incentivos para produção. Preocupados com esta situação, um grupo de agricultores na região noroeste do Estado do RS passou a discutir meios de enfrentar as dificuldades, sendo a casa veterinária Elmers (Ijuí) utilizada muitas vezes para estes encontros.

Após vários encontros, discussões e reuniões, em uma tarde chuvosa numa das salas do Clube Ijuí, aos 20 dias de julho de 1957, realizou-se a assembleia histórica de fundação da então Cooperativa Tritícola Serrana Ltda. Seu objetivo inicial era de "congregar os plantadores de trigo da região, para promover a defesa de seus interesses econômicos (...), e superar as dificuldades de comercialização da safra de trigo que vem se avolumando de ano para ano" (Carta ao jornal Correio Serrano, de Ijuí, em 24/07/1957).

Diante dos desafios a Cotrijui sempre buscou consolidar a filosofia de somar esforços e buscar soluções que atendessem o interesse coletivo. Esse foi o alicerce necessário para o crescimento do quadro social e a multiplicação dos investimentos e da capacidade de armazenagem de grãos, em diversas unidades que foram se espalhando pelo noroeste do Estado do Rio Grande do Sul, fronteira oeste, e região da campanha.

A Cotrijui diversificou suas atividades, ampliando suas ações através da agro industrialização, em especial na indústria de cereais, frigorífico, fábrica de rações e moinho, todas voltadas à agregação de valor no produto primário, buscando assim o melhor atendimento aos associados. É uma cooperativa de beneficiamento, industrialização e comercialização de produtos agropecuários, que presta assistência técnica direta aos associados, o que garante a qualidade da matéria-prima e o aumento da produtividade.

De toda a sua estrutura produtiva se pode destacar a soja, o trigo, o arroz, o milho, a canola, a aveia, o girassol, o leite e os suínos. Cabe explicitar que é através da cooperativa que se consegue chegar a milhares de consumidores de todo o Brasil e a diversos países ao redor do mundo pelas marcas Tchê, Cereais Cooper, Arroz Leviesti, Arroz Casabella, Rações e concentrados Vita Cotrijui, Sementes Cotrijui e, Massas Massolini.
Essas ações se revelam em números impressionantes. A Cotrijui recebe mais de 800 mil toneladas de produtos agrícolas e presta assistência à cerca de 1.500 produtores de leite, que somados produzem aproximadamente 70 milhões de litros de leite por ano, e abate anualmente cerca de 360 mil cabeças de suínos.

A cooperativa tem capacidade de armazenagem que supera 997 mil toneladas, em células dotadas de aeração e termometria, garantia de que a qualidade dos grãos, a ela confiados, será mantida. Os números e resultados da Cotrijui são expressivos e resultam do trabalho dos seus associados, distribuídos em mais de 42 municípios, somados a seus mais de 2.700 colaboradores. A Cotrijui representa mais de 19.200 associados distribuídos em mais de 42 municípios no Rio Grande do Sul. Tem sedes em Ijuí e Porto Alegre, frigorífico em São Luiz Gonzaga, pólo arrozeiro em Dom Pedrito e participação acionária no terminal do Porto de Rio Grande. Atualmente, a Cotrijui possui 13 unidades de negócios que abrangem mais de 42 municípios do Rio Grande do Sul.

Em se tratando do quadro social, a Cotrijui demonstra um crescimento constante quanto a essa questão. Para se ter uma ideia dessa expressiva em termos quantitativos, em 2002 a cooperativa tinha 12.751 associados. Passados 10 anos, o quadro social da Cotrijui expandiu-se para 19.347 associados, demonstrando em crescimento aproximado de $65 \%$.

Paralelamente a essa questão, é preciso explicitar de que forma esses associados estão estratificados quanto ao porte de cada um. Como se sabe, grande parte dos associados de cooperativas em geral são de pequeno porte. Esse cenário leva a duas concepções específicas, sendo a primeira que mostra que grande parte desses pequenos produtores não teriam condições de se inserir no mercado, caso as cooperativas não existissem, demonstrando fielmente o papel econômico e social dessas organizações; já a segunda concepção faz menção ao risco da atividade cooperativa em se tratando da dependência que há em relação aos grandes produtores, uma vez que em média estes são responsáveis por praticamente $80 \%$ da produção total. No caso da Cotrijui essa situação não é diferente uma vez que a estratificação dos produtores está representada, de forma aproximada, da seguinte forma: $3 \%$ grandes produtores, $6 \%$ médios produtores, $24 \%$ pequenos produtores e $67 \%$ mini produtores.

Em termos de colaboradores a Cotrijui também apresenta crescimento, fato este justificado, pois em 2002 a cooperativa contava como 1.324 colaboradores. Em 2012 houve um crescimento aproximado de $100 \%$, uma vez que cooperativa passou a contar com 2.674 colaboradores. Chama a atenção uma pequena redução em 2013, uma vez que o número atual de colaboradores está em 2.598 colaboradores. Essa redução foi justificada pelos entrevistados como uma necessidade de reestruturação da estrutura organizacional da cooperativa de modo a atender demandas da nova diretoria em relação sua 
saúde financeira.

Outra particularidade da Cotrijui está na Associação dos Funcionários da Cotrijui - AFUCOTRI. Essa associação é uma entidade social, esportiva, educativa e assistencial. Tem por objetivo promover a confraternização entre seus associados e dependentes, possibilitando momentos esportivos, recreativos e de lazer para os mesmos. Com uma área verde de aproximadamente $78.000 \mathrm{~m}^{2}$, dentro da qual se encontra, camping com toda a infraestrutura necessária, churrasqueiras, bar, piscinas, campos de futebol, salão de festas, quadra de vôlei, cancha de bocha, além de toda segurança. Possui uma área de lazer que proporciona a satisfação e o bem estar dos seus convidados, sempre levando em consideração que a confraternização, a realização de promoções artístico-culturais, sociais e o desenvolvimento de práticas esportivas são os principais objetivos da associação.

\subsection{O modelo de controle interno da Cotrijui versus o modelo teórico de Crepaldi (2007)}

Crepaldi (2007) assevera que o princípio da responsabilidade indica atribuições para os funcionários, devendo ser claramente definidos e limitados, de preferência por escrito, mediante as normas estabelecidas pela administração da empresa.

Ao se realizar a investigação quanto ao atendimento desse princípio nas rotinas da Cotrijui, indagou-se a respeito da atribuição de responsabilidades existente na cooperativa. Como respostas, pode-se considerar que as mesmas foram altamente positivas, pois para aproximadamente $77 \%$ dos resultados mostrou que há concordância total em relação à esse item em termos de aplicação na Cotrijui. Em concordância, algumas respostas foram extremamente objetivas e expressam com clareza como funciona esse processo na Cotrijui. "Existem responsabilidades definidas por setores ou áreas de negócio"; "com base no organograma da cooperativa, são atribuídas as responsabilidades de cada função"; "as responsabilidades são delegadas através do cargo que o colaborador ocupa e das respectivas funções de cada cargo"; "cada atividade dentro da cooperativa tem regras e procedimentos que devem ser cumpridos e cada encarregado tem como função principal fazer cumprir as rotinas".

Essas respostas mostram que há uma clareza quando à definição de atribuição de responsabilidades, reforçando conceitos apresentados por Crepaldi (2007) que assinala que as razões para se definir essas atribuições são: assegurar que todo o procedimento interno da empresa esteja sendo realizado de forma correta, detectar erros e irregularidades, apurar as responsabilidades por eventuais omissões, erros ou outro tipo de falha.

Já o princípio das rotinas internas versa para indicar a utilização de instrumentos de controles internos, ou seja, formulários, carimbos e outros mecanismos, que evidenciam e garantem que os procedimentos de controles internos sejam executados conforme as normas legais da empresa. A partir da análise dessa variável, observa-se que a existência de instrumentos e mecanismos de rotinas internas é percebida na cooperativa, uma vez que aproximadamente $70 \%$ dos entrevistados concordaram total ou parcialmente com essa afirmação. Algumas respostas transcritas confirmam esses resultados: "os instrumentos e mecanismos de controle são percebidos especialmente pelos objetivos e metas de cada setor da cooperativa, bem como de cada pessoa"; "esses instrumentos são definidos no planejamento estratégico e desdobrados em indicadores de acordo com cada setor da cooperativa"; "cada unidade tem disponível um sistema, em que pode checar o tipo de informação que querem, além do que via de regra cada unidade tem seu controle e responde pelo seu negócio"; "as rotinas são controladas por meio de sistemas de informação".

Porém chama a atenção que há uma discordância considerável, pois para $1 / 3$ dos questionados $(30,77 \%)$ os instrumentos e mecanismos de controle interno não são totalmente formalizados ou não chegam a todos os colaboradores. "Algumas pessoas não tem ideia clara da importância do seu trabalho na cooperativa, porque a falta uma orientação do chefe para tal situação"; "nem todos os cargos tem objetivos claramente definidos, eles são definidos mais em nível de setor"; "a falta de formalização das metas dificulta definir instrumentos de controle".

Uma segunda variável analisada no princípio das rotinas internas fez menção aos sistemas de orientação a respeito de procedimentos de trabalho de cada função. Nesse item, chama a atenção que $100 \%$ dos entrevistados concordaram total ou parcialmente com relação há existência de treinamentos específicos para tal variável do princípio das rotinas internas. Apenas para reforçar essa conclusão obtida a partir da análise da tabela anterior, algumas repostas mostram como essas orientações são feitas. "Quando o colaborador é contratado e este fará uso de rotinas de controle, o mesmo é submetido a um treinamento básico do sistema, que pode ser realizado tanto na matriz quanto na filial, dependendo do caso"; "os treinamentos normalmente são ministrados pelos funcionários mais antigos para os mais novos ou recémcontratados"; "as orientações são dadas pelas chefias, bem como pelos colegas mais próximos com quem essas pessoas irão trabalhar".

Quanto ao princípio do acesso aos ativos, Crepaldi (2007) contextualiza que o mesmo indica métodos de segurança que visam resguardar e controlar a existência física de ativos, fixar limites de autoridade para realizar determinada operação. Para isso, é importante que a empresa implante meios limitantes ao acesso dos mesmos, de modo que não interfira no desempenho normal das atividades diárias.

Em termos de questionamento para entender como 
esse processo de uso de medidas físicas para o acesso aos ativos, chamou atenção uma das respostas, considerada altamente detalhada. "São vários os níveis de acesso, onde foram criados níveis de acesso para consulta, níveis de acesso para contato físico, níveis de acesso para efetuar lançamentos no sistema e níveis de acesso para movimentações físicas. Na Cotrijui há um sistema de gestão e controle em nível de diretoria que é responsável por mapear todas as informações quantos aos níveis de acesso, e essas informações são geradas pelos sistemas setoriais com base no acesso de cada um deles"; "as medidas de controle de acesso são mais voltadas para que a informações sejam preservadas na sua íntegra, mas especialmente para evitar que os produtos sejam furtados, danificados ou adulterados. Não estou dizendo que nossos colaboradores fazem isso, mas a finalidade desse tipo de ação é mais para preservação de todos, ou seja, da cooperativa, do colaborador e do associado".

As respostas obtidas aqui permitam construir um mapa claro para entender como se dá a aplicação do princípio do acesso aos ativos na Cotrijui, especialmente quando à existência de medidas físicas para o controle do acesso a esses ativos.

No quarto princípio de análise quanto ao controle interno, emerge a questão da segregação de funções que segundo Crepaldi (2007) consiste em que uma pessoa não tenha o domínio completo sobre uma determinada operação, pois atua como uma medida preventiva para que qualquer erro intencional ou não que ela cometa possa ser detectado de imediato por outra pessoa.

As respostas apresentadas para essa variável foram relativamente poucas em termos descritivos, porém duas delas puderam dar uma ideia de como isso funciona de geral em termos do conjunto total da cooperativa, bem como de um setor em particular. "Pelo porte da cooperativa, há uma clara divisão entre as funções que compõem a organização e como cada pessoa responde para cada parte das atividades. Cada setor da cooperativa deve ter bem claro quais são as responsabilidades específicas de modo que possa dividir essas responsabilidades entre todos que fazem parte de tal setor. Um exemplo é na área de contabilidade, onde cada pessoa tem atribuições específicas de acordo com a sua área de atuação, como é o caso da área de custos, da área tributária estadual, área tributária federal, dentro outros"; "as funções são determinadas conforme o conjunto de necessidades do tipo de setor ou do tipo de negócio da cooperativa, sempre obedecendo a um padrão pré-estabelecido com base no organograma".

No princípio do confronto com os ativos, Crepaldi (2007) recomenda que os ativos da entidade (dinheiro, cheques, títulos de créditos, estoque, entre outros), sob responsabilidade de alguém (funcionários ou terceiros), sejam periódicamente confrontados com os registros da contabilidade e de controles internos. O objetivo é detectar fraude de bens ou até mesmo de registro contábil inadequado de ativos.

O que foi observado a respeito desse princípio pode ser descrito com maior detalhamento. "Mensalmente ou sempre que necessário é feito um inventário físico e confrontado com os registros dos estoques na contabilidade"; "temos um sistema de informações que faz a coleta dos dados por meio dos registros e através de relatórios de pré-balanço temos como fazer acompanhamento e monitoramento"; "com base no levantamento físico, balanços e amostragens, levantados com listagens e coletores de dados podemos realizar o confronto com softwares do sistema de informações".

Também se questionou aqui se, devido à possiblidade de falhas de funcionamento desse sistema, existe alguma contagem física e o respectivo confronto físico com o sistema. "Isso é feito para alguns produtos, pois no caso da soja é difícil contar, mas quando esvazia o armazém tem que dar um resultado, não tem que sobrar, pode até dar alguma sobra em função das taxas. Outra questão mais prática é quanto aos insumos, onde há a fiscalização por parte do conselho fiscal, que faz o inventário, sendo tudo isso feito sem avisar, ou seja, eles vão checam e confrontam se o que tem no físico tem no sistema".

Foi investigada ainda a ocorrência de perdas de insumos, como respostas se obtiveram que "no supermercado está perda é grande. Postos de combustíveis é muito pouco. De grãos, nós não perdemos no transporte, pois é o associado que perde para trazer e o que vendemos é responsabilidade de quem comprou. Na agroindústria é importante que tenhamos que rastrear no sistema os níveis de produtos que entram e saem, porque esse trabalho envolve pessoas, que estão sujeitas a cometer erros ou até mesmo desvios".

Devido ao grau de dependência do sistema de informações, questionou-se sobre a guarda dessas informações. "A nível de segurança do sistema, nós temos armazenamento de informações que é gerado fora da sede da cooperativa e tudo é arquivado fora da cooperativa. Há também a opção de guardar em papel, mas não se usa muito, pois tem que ter espaço para guardar e gera um custo considerável. Mas as falhas acontecem, como a vida toda nós vínhamos trabalhando com sistema próprio e tínhamos uma segurança, isso muitas vezes levava a surpresa desagradáveis. Hoje o sistema é terceirizado junto a uma empresa do Paraná, mas também é sujeito à falhas, então temos que estar sempre atentos".

O penúltimo item de análise do controle interno promove um debate sobre o princípio da amarração do sistema, o qual destaca que todas as operações da empresa sejam registradas com correção, tanto em termos de valores, quanto de quantidade, que sejam devidamente autorizadas e que qualquer falha seja possível ser detectada (CREPALDI, 2007).

De modo especial, é preciso considerar que esse princípio apresentou algumas de suas respostas já fun- 
damentadas na discussão anterior sobre o princípio do confronto com os ativos quando foram analisadas às variáveis contagem física e confronto dos ativos com os registros. No entanto, se aprofunda um pouco sobre essa discussão trazendo os resultados referentes ao princípio da amarração do sistema quanto à variável integração do sistema.

Como respostas para esse item em particular, temse que "do ponto de vista de sistemas, os mesmos são integrados e comunicam-se via arquivos específicos de acordo com sua função, sendo consolidados diariamente com base nas informações do sistema contábil"; "temos um sistema informatizado que auxilia na integração das diferentes informações e dados dos diferentes setores e atividades da cooperativa, sendo consolidados sempre que necessário".

Porém, uma das respostas apontou para a necessidade de uma revisão sobre a eficácia do modelo de amarração do sistema empregado na Cotrijui. "Existem alguns sistemas de informações isolados, que não possuem interface entre si, mesmo que esses sistemas trabalhem dentro dos mesmos setores". Nesse sentido, é preciso considerar que a importância da amarração do sistema se faz presente na medida em que ele oferecer uma série de informações diárias sobre as mais diferentes áreas de atuação da organização e sua importância está diretamente relacionada ao processo decisório como um todo.

Finalmente, o último princípio do controle interno analisado é o princípio da auditoria interna, teorizado aqui por Lopes de Sá (2000) como sendo o mais importante, porque a falta de observância deste pode consistir no não funcionamento dos demais princípios. Para o autor, não adianta a organização implantar um excelente sistema de controle interno, sem que alguém verifique periodicamente se os funcionários estão cumprindo o que foi determinado no planejamento, ou se há necessidade de serem adaptadas às novas técnicas adequadas às necessidades da empresa.

Dessa forma, podem ser apresentadas algumas respostas obtidas referentes à conteúdos relevantes descritos na sequência. "A Cotrijui não possui um sistema de auditoria interna"; "ainda encontra-se em fase de implantação esse item"; "existem iniciativas pontuais quanto à auditoria interna, porém a cooperativa está trabalhando essa questão em um nível mais global"; "o sistema informatizado está sendo preparado para obtermos relatórios de auditoria interna em casos de ocorrência divergentes aos das rotinas definidas"; "a cooperativa já teve um programa de auditoria interna, mas já faz muito tempo que deixou de existir, porém, eu sei que existe intenção de voltar a ter"; "já tivemos uma equipe bem estruturada de auditoria interna, mas ela deixou de atuar. Além disso, tínhamos também uma equipe de auditoria externa, mas hoje é o conselho fiscal que assumiu esse papel".

Cabe elucidar ainda que outros questionamentos surgiram a partir da investigação desse princípio como, por exemplo, sobre a importância da auditoria interna. Uma das respostas apontou que "eu acho muito importante por dois aspectos. Um pela verificação e avaliação constante que auditoria pode oferecer e outro porque se as pessoas sabem que ela existe e é atuante, isso inibe o ato ilícito. $\mathrm{O}$ simples fato das pessoas saberem que se tem uma auditoria, que ela está circulando, que a qualquer momento pode bater lá para ver o que a pessoa fez"; "uma das intenções é criação de um órgão de controladoria que em a função além de auditar todas as ações da cooperativa, terá também uma função gerencial em termos de apoio à diretoria, pois oferecerá indicadores para essa nova estrutura administrativa enquanto informações para as decisões".

Da mesma forma que explicitado anteriormente sobre o modelo de gestão da Cotrijui, de modo a oferecer um entendimento mais objetivo acerca da aplicabilidade do modelo de controle interno e suas correlações com o modelo teórico de Crepaldi (2007), apresenta-se no quadro 2, uma representação sintetizada que leva em conta o grau de atendimento ao elemento de análise, no caso o princípio, e suas respectivas categorias de análise, nesse caso tratando-se das variáveis.

Para que se pudesse fazer uma análise quantitativa mais objetiva, tomou-se como base a média do percentual das respostas quanto às escalas 'concordo totalmente' e 'concordo parcialmente', dado seu grau de aproximação para medir e avaliar a aplicabilidade do modelo estudado. De modo a qualificar as questões quantitativas, estabeleceu-se a seguinte lógica de enquadramento: de 0,00\% a 25,00\% - insuficiente; de $25,01 \%$ a 50,00\% - baixo; de $50,01 \%$ a $75,00 \%$ - médio; de $75,01 \%$ a $100,00 \%$ - alto.

De maneira prática, o que se pôde observar é que os princípios da responsabilidade, de rotinas internas e de confronto com as ativos têm o maior índice percentual em termos de grau de atendimento em relação ao modelo proposto por Crepaldi (2007). Já os princípios do acesso aos ativos, segregação de funções e amarração sistema tem um grau de adequação considerado médio. Por fim, o princípio da auditoria interna contemplou o princípio do controle interno de menor grau de adequação em relação ao modelo estudado.

\section{Conclusão}

Visando responder perguntas de pesquisa e atender ao objetivo geral apontado na introdução desse trabalho a dissertação, tem-se que é notória a ampla possibilidade de aplicação das metodologias de controle interno nas cooperativas.

A necessidade de sistemas de controle interno emerge por uma série de fatores, dentre os quais se destacam as mutações constantes que as organizações realizam nas atividades negociais em geral, o ritmo acelerado das 


\begin{tabular}{|c|c|c|}
\hline Princípio & Percentual & Grau de atendimento \\
\hline Responsabilidade & 100,00 & Alto \\
\hline Rotinas internas & 84,63 & Alto \\
\hline Acesso aos ativos & 61,54 & Médio \\
\hline Segregação de funções & 69,25 & Médio \\
\hline Confronto com os ativos & 80,77 & Alto \\
\hline Amarração do sistema & 69,25 & Médio \\
\hline Auditoria interna & 46,15 & Baixo \\
\hline
\end{tabular}

Quadro 2 - Comparativo ferramentas de controle interno da Cotrijui e o modelo de Crepaldi (2007) Fonte: pesquisa

mudanças ambientais e o maior acesso à tecnologia em nível domiciliar e organizacional.

É mister destacar uma vez mais que o presente estudo teve como objetivo identificar e analisar as ferramentas de controle interno aplicados na Cotrijui. Esse item do trabalho foi amplamente satisfeito, pois permitiu a identificação e o confronto das ferramentas de controle interno mais eficientes para a atividade cooperativa.

Resumidamente, o que se pôde observar é que os princípios da responsabilidade, de rotinas internas e de confronto com as ativos têm o maior índice percentual em termos de grau de atendimento em relação ao modelo proposto por Crepaldi (2007). Já os princípios do acesso aos ativos, segregação de funções e amarração sistema tem um grau de adequação considerado médio. Por fim, o princípio da auditoria interna contemplou o princípio do controle interno de menor grau de adequação em relação ao modelo estudado.

A partir do momento em que fundamentos teóricos foram avaliados e salientados, dados foram coletados, analisados e descritos a partir de aspectos metodológicos e diagnósticos e ainda, modelo proposto, torna-se possível a apresentação de algumas recomendações, pautadas pela conclusão apresentada. Dessa forma, é possível abstrair determinados elementos que agrupam recomendações que tem como finalidade máxima o aperfeiçoamento das ideias sugeridas, dentre as quais destacam-se:

Finalizando, cabe enfatizar que esse estudo fundamentou-se numa pesquisa qualitativa em um único caso prático e não teve o propósito de generalizar resultados e nem mesmo exaurir os estudos ou tirar conclusões ousadas de um tema tão complexo e importante como a gestão de organizações cooperativas. Por esse motivo a realização de outros estudos em cooperativas de outras partes do Estado e do País e a investigação de outros fatores inerentes às metodologias de controle interno, a partir de novos pressupostos teóricos e práticos são considerados pontos fundamentais para aprofundar essa discussão.

\section{Referências}

ATTIE, W. Auditoria conceitos e aplicações. São Paulo: Atlas, 1998.

BELL, J. Projeto de pesquisa: guia para pesquisadores iniciantes em educação, saúde e ciências sociais. Porto Alegre: Artmed, 2008.

BIALOSKORSKI NETO, S. Agronegócio Cooperativo. In: BATALHA, M. Gestão agroindustrial. São Paulo: Atlas, 2001.

BOESCHE, L.; MAFIOLETTI, R. L. Evolução e indicadores do cooperativismo brasileiro e paranaense. Curitiba: SISTEMA OCEPAR. 2005.

CERVO, A.; BERVIAN, P. Metodologia científica. São Paulo: Pearson Prentice Hall, 2006.

CONSELHO FEDERAL DE CONTABILIDADE. Princípios fundamentais da contabilidade e normas brasileiras de contabilidade. NBC TA 315 Controle interno. Disponível em <http//: www.cfc. org.br>. Acesso em: 01 mar. 2012.

COOPERATIVA AGROPECUÁRIA E INDUSTRIAL. Disponível em <http: //www.cotrijui.coop.br> Acesso em: 02 mai. 2013.

CORDEIRO, M. A. N.; DANTAS, M. Z.

Importância do planejamento estratégico para o desenvolvimento de empresas cooperativas. In: V Encontro de pesquisadores Latino-Americanos de cooperativismo. Agosto, 2008. Ribeirão Preto, SP, Brasil. Disponível em: <http://www.fundace.org.br/ cooperativismo> Acesso em: 25 abr. 2012.

CREPALDI, S. Auditoria contábil teoria e prática. São Paulo: Atlas, 2007. 
FRANCO, H.; MARRA, E. Auditoria contábil. São Paulo: Atlas, 2007.

GIL, A. C. Estudo de caso. São Paulo: Atlas, 2009.

HAIR JR, J. F. Fundamentos de métodos de pesquisa em administração. Porto Alegre: Bookman, 2006.

HORNGREN, C.; SUNDEM, G.; STRATTON, W. Contabilidade gerencial. São Paulo: ABDRD, 2004.

LAKATOS, E. M.; MARCONI, M. A. Metodologia do trabalho científico: procedimentos básicos, pesquisa bibliográfica, projeto e relatório, publicações e trabalhos científicos. São Paulo: Atlas, 2001.

LOPES de SÁ, A. Curso de auditoria. São Paulo: Atlas, 2000.

PEREIRA, B. A. D.; VENTURINI, J. C.; CERETTA, P. S.; DUTRA, V. R. Análise da eficiência em cooperativas agropecuárias no estado do Rio Grande do Sul. Revista Universo Contábil - FURB, v. 5, n. 2, 2009.

PINHEIRO, S. F. C.; SILVA, T. C. Desafios da gestão das cooperativas de consumo: estudo de caso. In: I Encontro Brasileiro de Pesquisadores em Cooperativismo (EBPC). Brasília, 2010.

RESKE FILHO, A.; JACQUES, E. A.; MARIAN, P. D. O controle interno como ferramenta par o sucesso empresarial. Revista do Centro de Ciências Sociais e Humanas - UFSM, Santa Maria, v. 18, n. 2, 2005.

RUIZ, J. A. Metodologia científica. São Paulo: Atlas, 2004.

SAMPIERI, B.; COLLADO, R. S.; LUCIO, M. Metodologia de pesquisa. São Paulo: Atlas, 2006.

TÁLAMO, J. R.; CARVALHO, M. M. Seleção dos objetivos fundamentais de uma rede de cooperação empresarial. Revista Gestão e Produção, v. 11, n. 2, 2004.

YIN, R. Estudo de caso: planejamento e métodos. Porto Alegre: Bookman, 2003.

ZANETTE, M. A.; NASCIMENTO, C.; ALBERTON, L. A sistemática de procedimentos analíticos em auditoria externa aplicada em cooperativa de crédito. SIMPOI - Simpósio de Administração da Produção, Logística e Operações Internacionais, v. 2, n. 4, 2009. 
